\title{
A novel kind of tumor type-characteristic junction: plakophilin-2 as a major protein of adherens junctions in cardiac myxomata
}

\author{
Steffen Rickelt ${ }^{1,8}$, Stefania Rizzo ${ }^{2,8}$, Yvette Doerflinger ${ }^{1,3}$, Hanswalter Zentgraf ${ }^{4}$, \\ Cristina Basso ${ }^{2}$, Gino Gerosa ${ }^{5}$, Gaetano Thiene ${ }^{2}$, Roland Moll ${ }^{6}$ and Werner W Franke ${ }^{1,7}$ \\ ${ }^{1}$ Helmholtz Group for Cell Biology, German Cancer Research Center, Heidelberg, Germany; ${ }^{2}$ Department of \\ Medical-Diagnostic Sciences, University of Padua Medical School, Padua, Italy; ${ }^{3}$ Department of Dermatology, \\ University Hospital Mannheim, University of Heidelberg, Mannheim, Germany; ${ }^{4}$ Monoclonal Antibody \\ Facility, German Cancer Research Center, Heidelberg, Germany; ${ }^{5}$ Department of Cardiac, Thoracic and \\ Vascular Sciences, University of Padua Medical School, Padua, Italy; ${ }^{6}$ Institute of Pathology, Philipps \\ University Marburg, Marburg, Germany and ${ }^{7}$ Progen Biotechnik, Heidelberg, Germany
}

\begin{abstract}
Using novel antibodies of high avidity to-and specificity for-the constitutive desmosomal plaque protein, plakophilin-2 (Pkp2), in a systematic study of the molecular composition of junctions connecting the cells of soft tissue tumors, we have discovered with immunocytochemical, biochemical and electron microscopical methods, a novel type of adherens junctions in all 32 cardiac myxomata examined. These junctions contain cadherin-11 as their major transmembrane glycoprotein, which we could repeatedly show in colocalization with $\mathrm{N}$-cadherin, anchored in a cytoplasmic plaque formed by $\alpha$ - and $\beta$-catenin, together with the further armadillo-type proteins plakoglobin, p120, p0071 and ARVCF. Surprisingly, all adherens junctions of these tumors contained, in addition, another major armadillo protein Pkp2, hitherto known as an obligatory and characteristic constituent of desmosomes in epithelium-derived tumors. We have not detected Pkp2 in a series of noncardiac myxomata studied in parallel. Therefore, we conclude that this acquisition of Pkp2, which we have recently also observed in some mesenchymally derived cells growing in culture, can also occur in tumorigenic transformations in situ. We propose to examine the marker value of Pkp2 in clinical diagnoses of cardiac myxomata and to develop Pkp2-targeted therapeutic reagents.
\end{abstract}

Modern Pathology (2010) 23, 1429-1437; doi:10.1038/modpathol.2010.138; published online 6 August 2010

Keywords: adherens junctions; differential histodiagnosis; myxoma; plakophilin-2; puncta adhaerentia

The identification of the specific types of transformed cells and of the kind and level of their differentiation is an essential part of tumor diagnosis, not only with respect to the histogenic origin but also as a basis for prognoses and therapeutic decisions. Therefore, molecular markers for cell typing and differentiation have become almost obligatory criteria in pathological diagnoses, in particular of epithelium-derived tumors, for which

Correspondence: Professor WW Franke, Helmholtz Group for Cell Biology, German Cancer Research Center, Im Neuenheimer Feld 581, Building TP4, Room S3.222, 69120 Heidelberg, Germany.

E-mail: w.franke@dkfz.de

${ }^{8}$ These authors contributed equally to this work.

Received 13 April 2010; revised 1 June 2010; accepted 7 June 2010; published online 6 August 2010 reliable immunohistochemical marker antibodies are used worldwide ${ }^{1-4}$ (for a review see Chu and Weiss ${ }^{5}$ ). However, in the field of mesenchymally derived tumors, the armamentarium of diagnostic markers is still relatively poor and problems of correct identification of certain soft tissue tumors are obvious. ${ }^{6,7}$ Therefore, we have recently begun to systematically determine the molecular composition of potential marker molecules of mesenchymal cell types and the diverse nonepithelial tumors derived therefrom. ${ }^{6-9}$

Surprisingly, already in our initial series of experiments, we have recognized unexpected changes in the molecular ensembles of cell-cell junctions of the adherens category. An especially eye-catching finding has been the phenomenon that a series of mesenchymally derived cells growing in 
culture, including human tumor cell lines, contain adherens junctions of a drastically altered composition. They are based on clusters of $\mathrm{N}$-cadherin or cadherin-11 anchored in a subplasmalemmal plaque, which contains $\alpha$ - and $\beta$-catenin plus several further proteins of the armadillo family such as plakoglobin and proteins p120, p0071 and ARVCF, and in addition also contains another major armadillo-type protein, plakophilin-2 (Pkp2). ${ }^{10,11}$ This rapid acquisition of $\mathrm{Pkp} 2$ is perplexing, as plakophilins hitherto have only been known as obligatory molecules specific for desmosomes of epithelial and myocardiac cells as well as of epithelium-derived tumors, including all carcinomas.

We have also noted occasional groups of cells in sections of some tumors of mesenchymal origin, which in immunohistochemistry show adherens junctions positive for $\mathrm{Pkp} 2$, indicating that this change in molecular composition of the adherens junctions may also take place during tumor formation in situ. Consequently, we have examined the molecular composition of adherens junctions connecting the cells of various soft tissue tumors. Here, we present as a first result our finding that all adherens junctions connecting cardiac myxoma cells show exactly such a general acquisition of Pkp2.

\section{Materials and methods}

\section{Antibodies}

To generate highly sensitive antibodies specific for Pkp2 that could also be used on aldehyde-fixed and paraffin-embedded tissues, we have used peptides derived from promising, epitope-containing regions of the human Pkp2 amino-acid (aa) sequence (aa positions 820-837, representing the carboxyterminal aa sequence KTDFVNSRTAKAYHSLKD, and aa positions 611-625; ie, VKEQYQDVPMPEEKS, representing a segment at the border between armadillo repeats 5 and 6), and conjugated them to keyhole limpet hemocyanin for the immunization of guinea pigs (for details of the molecule and of immunization protocols see Mertens et $a l^{12}$ ). The polyclonal antibodies selected, termed PP2-hCT (for the carboxy-terminal sequence) and PP2-hM (for the armadillo repeat 5/6 border domain), were of excellent stability and accessibility in biochemical and immunological experiments.

Murine monoclonal antibodies (mAbs) to Pkp2 were generated by immunization of BalbC mice, using peptides derived from aa position 527-872 of the human protein (for method see Holmdahl et $a l^{13}$ ). The supernatants of the resulting monoclonal hybridoma cell cultures were screened by immunofluorescence microscopy using methanol/ acetone-fixed epithelial cell cultures (for protocol see Supplementary Information) and tested by immunoblotting of total cellular proteins separated by SDS-PAGE. In addition, we specifically screened for immunostaining reactivity on formaldehydefixed cultured cells and tissue blocks (see below). From a total of ca. 2000 different hybridomas, 3 mAbs (Pkp2-402, Pkp2-407 and Pkp2-518) were prepared in sufficient amounts and characterized in detail. All antibodies routinely used are listed in Supplementary Table $1 .^{11,14}$

\section{Tissues}

A total of 32 frozen and formaldehyde-fixed and paraffin-embedded samples of human tissues, including a large series of different myxoma types (see Supplementary Information), have been examined. Special diagnostic care was taken to ensure that no malignant heart tumors were included in the study. ${ }^{15}$ Samples of heart tissues obtained from various mammalian, avian, amphibian and fish species (cf. Barth et $a l^{10}$ and Pieperhoff and Franke ${ }^{16}$ ) were examined in parallel.

\section{Gel Electrophoresis and Immunoreactions of Proteins}

For preparations of control cell lysates, monolayer cell cultures were briefly rinsed twice with phosphate-buffered saline, suspended in sample buffer (250 mM Tris-HCl, 10\% SDS, $20 \%$ glycerol, $100 \mathrm{mM}$ dithiotreitol; $\mathrm{pH}$ 6.8) containing benzonase (1:1000; Merck, Darmstadt, Germany) and scraped off the dishes using a rubber policeman. Small pieces of frozen myxoma and control tissues were also homogenized in sample buffer containing benzonase. After vigorous vortex homogenization, lysates were heated for $5 \mathrm{~min}$ at $95^{\circ} \mathrm{C}$, briefly centrifuged and subjected to SDS-PAGE, followed by blot transfer to PVDF membranes (Millipore, Bedford, MA, USA), and reacted with horseradish peroxidase-conjugated secondary antibodies, applied in combination with a chemiluminescence system (ECL, AmershamBuchler, Braunschweig, Germany). ${ }^{11}$

\section{Results}

\section{Generation of Highly Sensitive Pkp2 Antibodies}

To detect Pkp2 deep in adherens junction plaques, notably epitopes masked by obscuring complexes (for nuclei see Mertens et $a l^{12}$ ), we have generated improved antibodies for immunohistochemistry. Figures 1a-c present two such reagents, a monoclonal and a polyclonal one, showing intense and specific immunoblot reactions, as well as immunostaining of the $\mathrm{Pkp} 2$ located in the composite junctions of the intercalated disks of the human heart (cf. Franke et $a l^{17}$ ). For comparison, Figures 1d and e show the very intense and desmosomespecific Pkp2 immunostaining in a section of a formaldehyde-fixed and paraffin-embedded tissue sample of human colon (Figure 1d) and on a monolayer of human breast carcinoma cells (line MCF-7) 
a
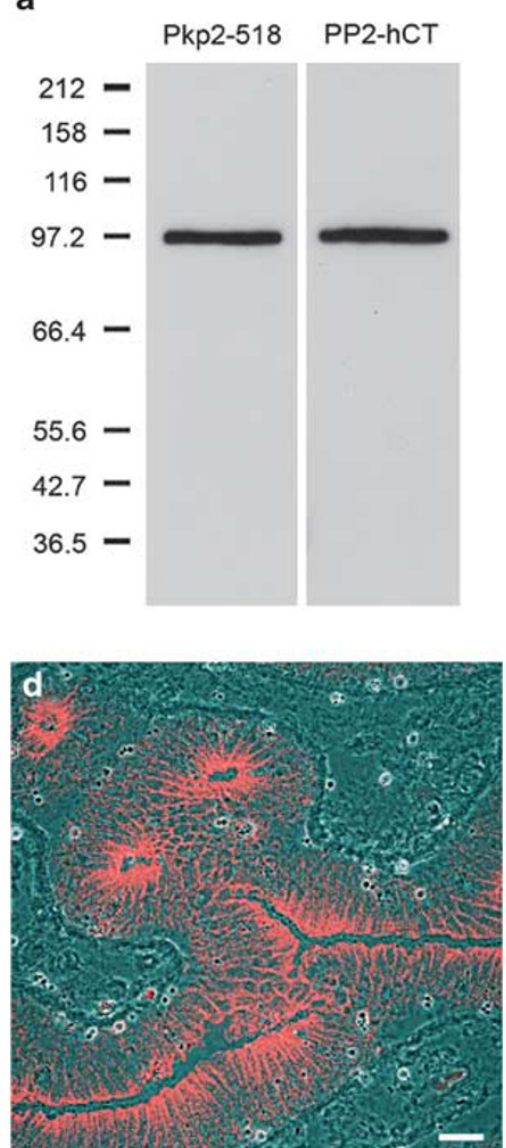
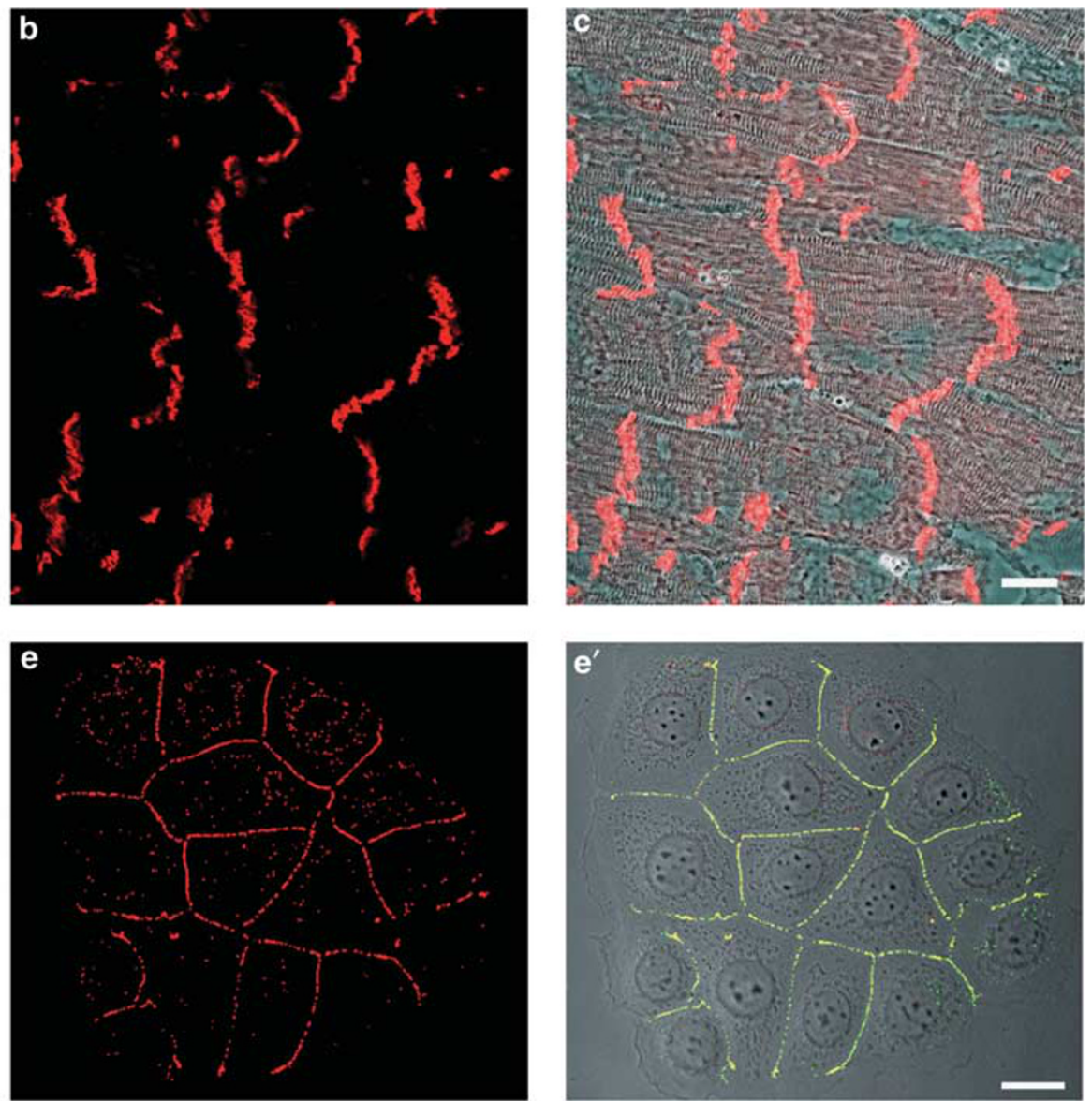

Figure 1 (a-c) Specificity of two of the newly generated plakophilin-2 (Pkp2) antibodies in their immunoblot and immunofluorescence reactions on human heart tissue proteins. (a) Lysates of total human myocardium, showing the reaction with a single polypeptide band of ca. $96 \mathrm{kDa}$, using monoclonal antibody (mAb) Pkp2-518 and guinea pig antibodies of antiserum PP2-hCT. Reference protein bands (on the left margin) give the molecular weight in $\mathrm{kDa}$ values. (b, c) Confocal laser scanning microscopy of paraffin-embedded human heart tissue, treated for antigen retrieval and reacted with mAb Pkp2-518 (red), shows a specific reaction of the composite junctions in the intercalated disks (b, fluorescence optics; c, fluorescence and phase contrast optics). (d-e') Confocal microscopy images showing the intense and specific reactions of mAb Pkp2-518 with desmosomes on a section of human intestinal tissue treated for antigen retrieval (d) and on a monolayer of cultured human cells of the breast carcinoma line MCF-7 (e, $\mathbf{e}^{\prime}$ ). (d) Immunofluorescence and phase contrast optics demonstrating that the immunofluorescent reaction is specific for the desmosomes of the epithelium. (e) The immunoreaction of Pkp2 (red) is detected in linear punctate arrays of small closely spaced reaction sites, representing desmosomes, and in some sparse and irregularly distributed cytoplasmic dots, representing endo- or exocytotic vesicles coated with a Pkp2-containing plaque. (é') Interference contrast color image of the same region, demonstrating the colocalization of Pkp2 and desmoplakin (green) in desmosomal plaques (yellow merged color) and in some cytoplasmic desmosomal plaque structures. Scale bars: $20 \mu \mathrm{m}$.

grown in culture (Figures $1 \mathrm{e}$ and $\mathrm{e}^{\prime}$ ). The latter illustration also demonstrates that the vast majority of Pkp2-positive sites colocalize with desmoplakin, the hallmark component of desmosomal plaques. Similarly brilliant results were obtained with numerous other tissues and with cell cultures of human or other mammalian origins.

We have recently reported that Pkp2 is not only a permanent constituent of true desmosomes of epithelial, myocardiac or meningeal tissues and of tumors derived therefrom and of the composite junctions of cardiomyocytes ${ }^{12,17,18}$ but can also be found in diverse lines of mesenchymally derived cell cultures. ${ }^{11}$ Therefore, we have decided to examine the possible presence of this plakophilin in adherens junctions of mesenchymal tumors.

\section{The Adherens Junctions Connecting Cardiac Myxoma Cells}

Cardiac myxomata are considered as benign tumors generally characterized by 'stellate' cells with variously long cell processes embedded in a jellylike mucoid extracellular matrix. ${ }^{19}$ They present a predominantly mesenchymal marker protein profile with abundant bundles of intermediate-sized filaments (IFs) of the vimentin type. Only in a minor proportion of cells in some of these tumors have we noted small groups of cells that are also positive for the IF protein desmin, whereas IFs containing any keratins, glia filament or neurofilament proteins have not been seen. Nonmuscle-type actin microfilaments are prevalent, but in a minor proportion of 
myxoma cells we have also detected $\alpha$-smooth muscle-type actin filaments but no sarcomeric $\alpha$-actins. All our general immunocytochemical observations in the 32 myxomata studied are grosso modo in agreement with most previous reports, indicating a derivation from cardiac mesenchymal cells ${ }^{20-29}$ (for occasional claims of special cardiac myxoma tumor cells showing keratin reactions, mostly in glandular elements, see references 24, 29, 30).

Most of the myxoma cells formed numerous cell processes and were interconnected into a loose irregular meshwork by punctum adhaerens-type junctions. Consequently, myxoma cells can occur in relatively close apposition, as shown in Figure 2, or distant from each other, connected only by rather thin, variously long, tentacle-like filopodial
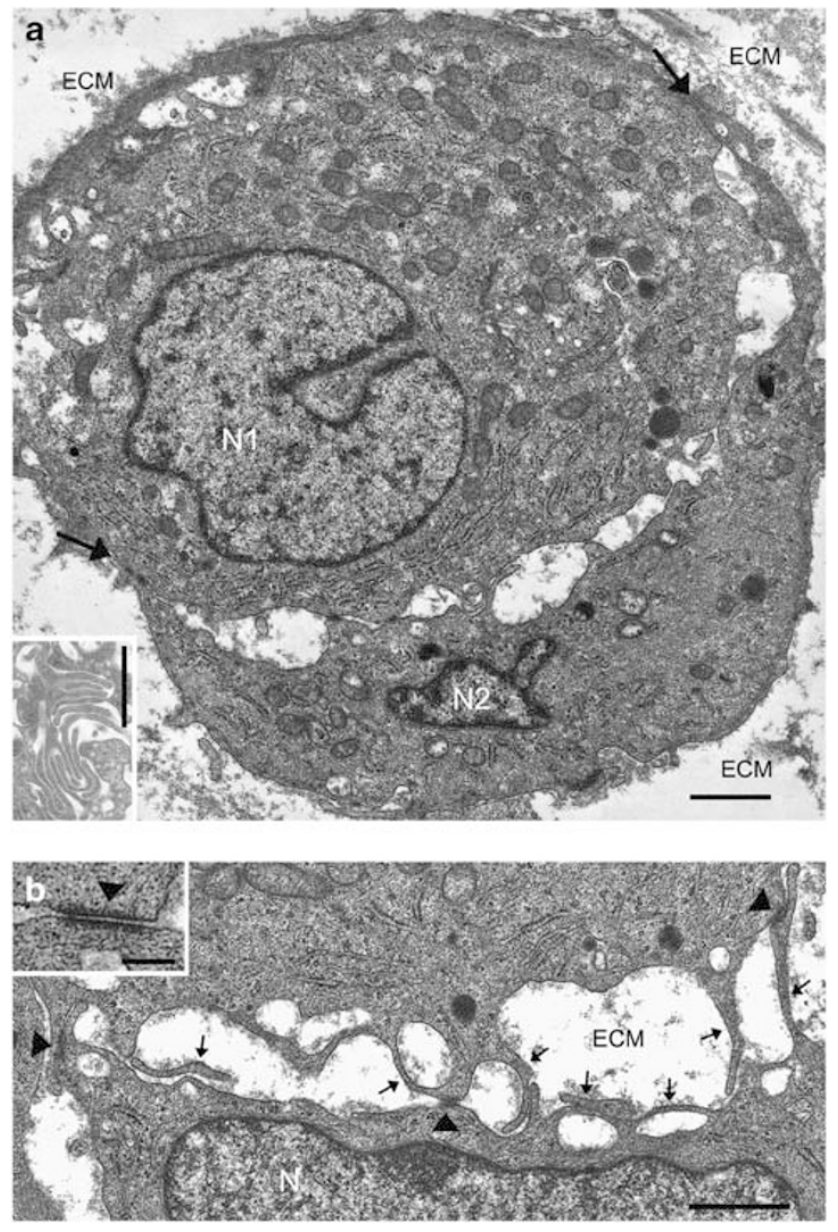

Figure 2 (a, b) Electron micrographs of cross-sections of adjacent cell borders in an atrial human myxoma, presenting numerous cell-cell contacts at protrusions or variously long filopodia-like processes, including highly folded and packed filopodia (an example is shown in the insert in the lower left). (a) Extended contact regions of central cell bodies (N1 and N2: nuclei of the two cells; arrows denote the ends of the contact zone), embedded in a loose extracellular matrix. (b) Higher magnification of a contact zone with numerous filopodia-like processes (arrows) that appear to be involved in cell-cell contacts, in specific places forming plaque-coated adherens junctions (arrowheads), one of which is shown in detail in the insert in the upper left. Scale bars: $1 \mu \mathrm{m}$ (a); $0.5 \mu \mathrm{m}$ (b and insert in a), $0.25 \mu \mathrm{m}$ (insert in b). cytoplasmic processes..$^{24,25}$ As the very short processes of perinuclear cytoplasm are adequately resolved only by electron microscopy, we show (Figure 2) an example of such an interaction through short processes and their adherens junctions, characterized by a thin (ca. $15 \mathrm{~nm}$ ) dense plaque (eg insert in Figure 2b), that is, myxoma structures that have repeatedly been described in literature as 'desmosome-like'.

\section{Biochemical Analyses of Adhering Junction Proteins}

Our systematic analyses of cryo-dissected tissue samples of various snap-frozen myxomata by SDSPAGE and immunoblotting revealed consistent but surprising results (Figure 3). The predominant transmembrane adherens junction glycoprotein identified was cadherin-11. Only in limited regions of some of the tumors was this glycoprotein accompanied by N-cadherin. VE-cadherin, on the other hand, was clearly seen in the zonulae adhaerentes of the endothelial structures of adjacent vascular elements but was totally absent from the myxoma cells proper (see also below). Moreover, we found all major adherens junctional plaque proteins such as $\alpha$ - and $\beta$-catenin, plakoglobin, protein p120 (Figure 3), as well as proteins p0071 and ARVCF (not shown).

Unexpectedly, however, we identified in all cardiac myxomata examined the plaque protein Pkp2 (Figure 3 presents examples from six different tumors analyzed in parallel in the same SDS-PAGE), often together with varying proportions of an immunoblot-positive polypeptide of ca. $70 \mathrm{kDa}$, obviously a distinct proteolytic breakdown product. In a few tumor samples, we have also noted the additional presence of minor amounts of Pkp3 (not shown), but we have never detected Pkp1. Tests for the most predominant protein in desmosomal plaques, desmoplakin, were negative in all myxoma cells of all cases (not shown).

\section{Immunolocalization Studies}

The mostly rather small adherens junctions, which connect the cardiac myxoma cells in their nucleuscontaining central cell bodies, as well as in their slender processes, are recognized by the colocalization of Pkp2 with typical adherens junction markers such as $\alpha$ - and $\beta$-catenin, plakoglobin and proteins p120, p0071 or ARVCF, as demonstrated by their yellow to orange merge color (eg, see Figures 4a and $b$ ). This is in distinct contrast to the absence of Pkp2 from the adherens junctions connecting the vascular endothelial cells (note the green immunostaining for $\beta$-catenin in Figure 4a). In the myxoma cell processes, the adherens junctions are often clustered, resulting in continuously yellow immunostaining (Figure 4b) or in closely spaced Pkp2reactive punctate or 'beaded' arrays (Figures $4 \mathrm{~b}-\mathrm{e}$ ). 

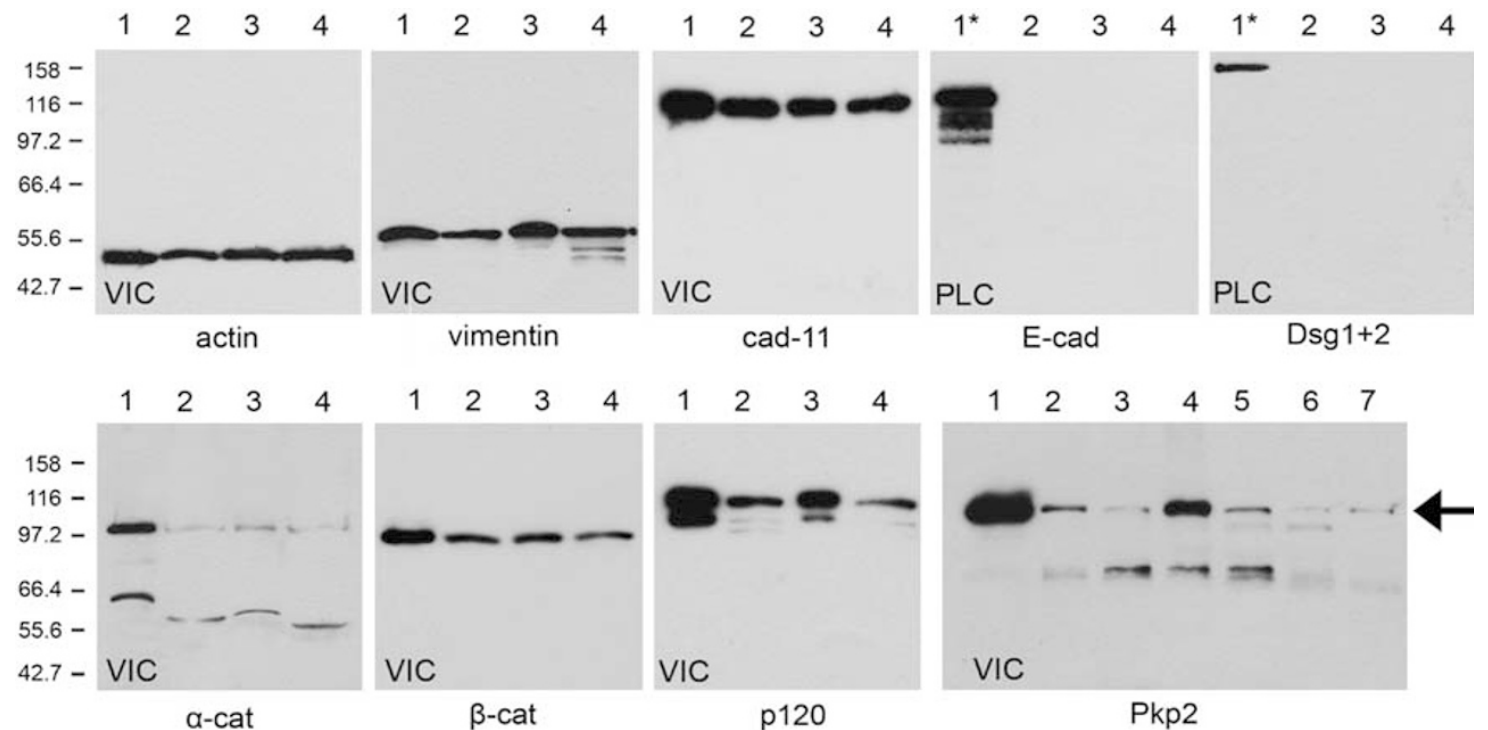

Figure 3 Immunoblot detection of adherens junction proteins in human myxomata as revealed by SDS-PAGE-separated total cytoskeletal proteins and western blots, in comparison with such proteins from cultured human valvular interstitial cells (VIC, lane 1; cf. Barth $e t a l^{10}$ ) or with junctional proteins from cultured human liver carcinoma cells of line PLC (primary liver carcinoma; lane 1 with asterisk). Samples from the following myxoma tumors (numbers) are shown here: 1046-06 (lane 2), 1236-08 (lane 3) and 1334-08 (lane 4). Proteins were probed with antibodies specific for actin and vimentin, cadherin-11 (cad-11) and E-cadherin (E-cad), in comparison with the desmosomal cadherins desmogleins 1 and 2 (Dsg1 +2 ), as well as adherens junction plaque proteins $\alpha$ - and $\beta$-catenin or protein p120. Note that, besides the intermediate-sized filament (IF) protein vimentin, all adherens junction proteins tested, including cad-11, $\alpha$ - and $\beta$-catenin, as well as protein p120, can be detected in the cardiac myxomata. Plakophilin-2 (Pkp2) is shown, at different intensities, as a polypeptide band of ca. $96 \mathrm{kDa}$ (arrow at right hand margin) whereas other epithelial marker proteins such as E-cad and desmogleins have been absent in all myxoma samples examined. To show the general occurrence of Pkp2, samples from six different myxomata are presented here. Total proteins of myxoma samples were applied as follows (cardiac myxoma tumor numbers given): 136307 (lane 2) and 1334-08 (lane 3), 1236-08 (lane 4), 1046-06 (lane 5), 531-07 (lane 6) and 197-07 (lane 7). Positions of polypeptide molecular weights are indicated on the very left margin and correspond to 158, 116, 97.2, 66.4, 55.6 and $42.7 \mathrm{kDa}$ (from top to bottom). Note also the appearance of a major proteolytic Pkp2 fragment at ca. $70 \mathrm{kDa}$. *For the immunoblot identification of E-cadherin and Dsg2 whole-cell lysates of human liver carcinoma cells of line PLC were loaded as positive control, instead of interstitial cells from cardiac valves.

Colocalization of Pkp2 was also obtained with both cadherins mentioned. Cadherin-11 generally colocalized with Pkp2 in serial arrays of yellow dots or in beaded chains of adherens junction structures (eg Figures 5b and c) in the same way as it reacted with $\beta$-catenin and other plaque proteins (Supplementary Figures 1a-e). Similar observations were made with $\mathrm{N}$-cadherin, which appeared only in adherens junctions of certain limited regions in some of the tumors (eg Figure 5a). Again, all these adherens junction reactions fully contrasted with those of the endothelium of the adjacent vessels (see the red $\beta$-catenin reaction in both Figures $5 \mathrm{a}$ and $\mathrm{b}$ ). In control experiments, VE-cadherin antibodies reacted only with the endothelial junctions, which otherwise contained all the plaque proteins mentioned above, with the exception of Pkp2 (not shown). As a positive colocalization control for junctional plaque immunostaining in the zonulae adhaerentes of vascular endothelium, an $\alpha$-catenin example is shown in Supplementary Figure 1f.

Much to our surprise we have not detected a Pkp2-positive adherens junction in any of the six noncardiac myxomata examined in parallel (Supplementary Table 2).

\section{Discussion}

The molecular analysis of the cell-cell junctions in cardiac myxomata has led to the unexpected identification of a novel adherens junction type, the Pkp2-containing one, hitherto only known as coniunctio adhaerens of certain cell cultures ${ }^{10,11}$ (for review see Franke et $a l^{35}$ ). Obviously, this adherens junction type represents a cell-cell connecting structure of its own kind, which is characteristic for certain tumors, as shown here for cardiac myxomata. So far, this type of junction has only sporadically been noted in some isolated cells or cell groups in a rhabdomyosarcoma. ${ }^{11}$

The mostly rather small, roundish-to-oval adherens junctions identified as the major myxoma cell-cell contacts represent typical mesenchymal structures, albeit with a special molecular composition. In these junctions, we have detected cadherin-11 as the only ubiquitous transmembrane glycoprotein, whereas additional $\mathrm{N}$-cadherin was seen only in restricted regions of a few tumors, which we also take as an indication of the existence of two myxoma cell subtypes distinguished by their adherens junction composition, one with 

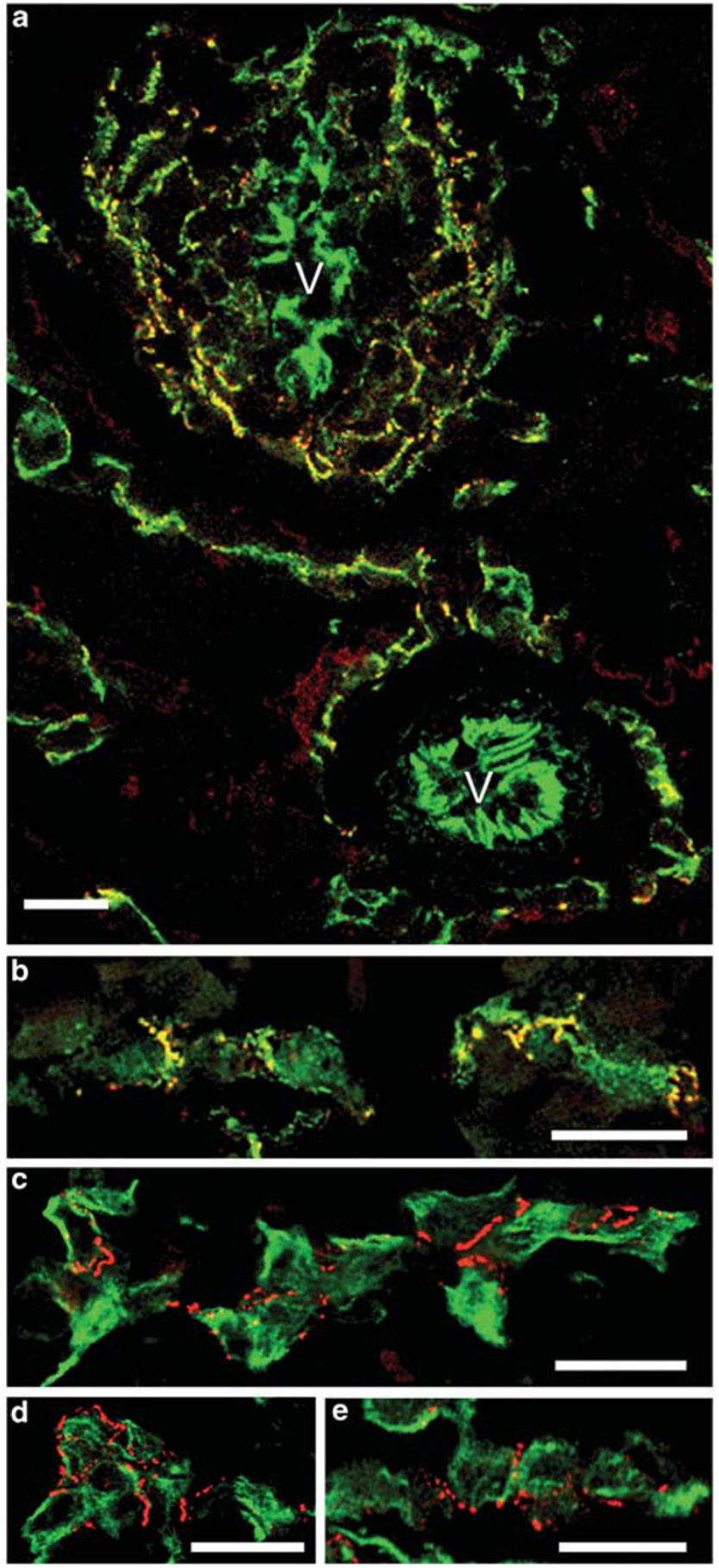

Figure 4 Localization of plakophilin-2 (Pkp2) in adherens junctions of diverse cardiac myxomata. Sections of paraffinembedded human myxomata were treated for antigen retrieval and double-immunostained with antibodies to Pkp2 (red) in combination with antibodies to $\beta$-catenin (a, b, green) and vimentin (c-e, green). Note the extensive colocalization (yellow) of Pkp2 and $\beta$-catenin in adherens junctions of intervascular myxomata (a), as well as in adherens junctions connecting extended processes of myxoma cells (b), whereas the adherens junctions connecting the vascular endothelial cells are negative for Pkp2. Note also that all cells positive for Pkp2 contain intermediate-sized filaments (IFs) of the vimentin type (c-e) and that the adherens junctions connecting myxoma cell processes are often clustered and thus appear in some situations as 'beaded' chains (c-e, red). V, vessel. Scale bars: $20 \mu \mathrm{m}$.

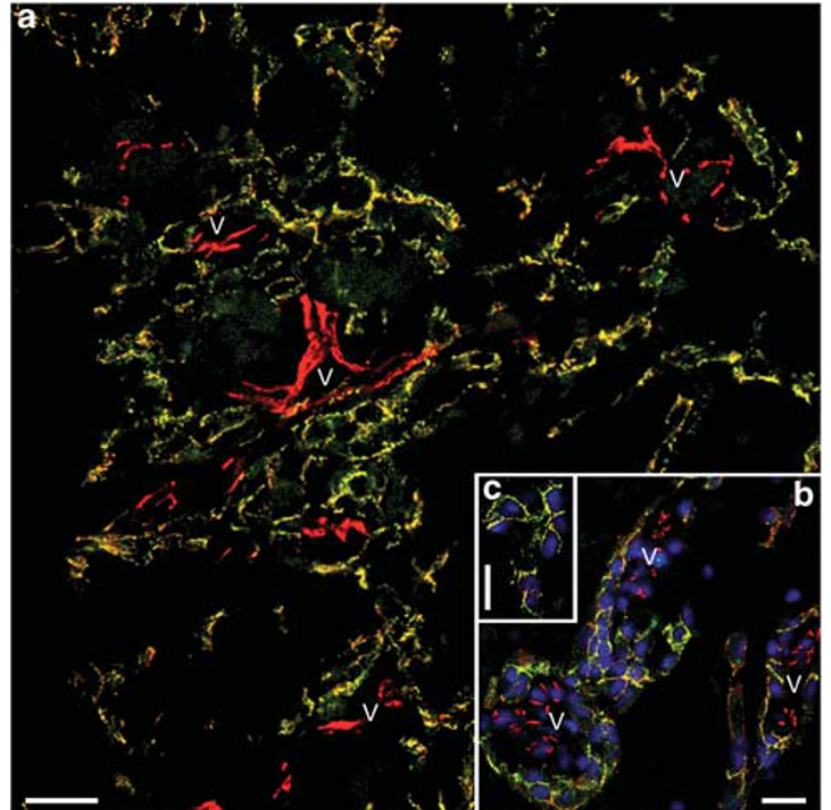

Figure 5 Immunofluorescence microscopy of sections of human myxomata treated for antigen retrieval and reacted with antibodies to the adherens junction plaque protein $\beta$-catenin (a-c, red), and the transmembrane glycoproteins $\mathrm{N}$-cadherin (a, green) or cadherin-11 (b, c, green). Note that both cadherins are prominent at cell-cell contact sites of the specific myxomata (yellow merged color) but not at the adherens junctions of the endothelial cells of vessels (V) which, however, are recognized here by their intense $\beta$-catenin immunostaining. (c) Magnification showing the colocalization (yellow) of the junctional plaque protein $\beta$-catenin (red) and the transmembrane cadherin-11 (green) in punctate series of distinct adherens junctions. DAPI stain (blue in $\mathbf{b}$ and $\mathbf{c}$ ) has been used to visualize nuclei. Scale bars: $20 \mu \mathrm{m}$.

cadherin-11 only and the other containing both cadherin-11 and $\mathrm{N}$-cadherin (for related observations, see Franke et $a l^{35}$ Franke, ${ }^{36}$ Strumane et $a l,{ }^{37}$ Butany et $a l,{ }^{38}$ Reynen, ${ }^{39}$ Pucci et $a l^{40}$ and Burke et $a l^{41}$ ). At present, however, we cannot rigorously exclude the alternative explanation that all myxoma adherens junctions may also contain some $\mathrm{N}$-cadherin, which tends to be rapidly degraded by some of the proteolytic enzymes known to occur in tissue preparations from these tumors. ${ }^{42}$

The molecular pattern of the adherens junction plaques of the cardiac myxomata is remarkably complex and specific. While most components identified, including $\alpha$ - and $\beta$-catenin, together with further armadillo proteins such as plakoglobin and proteins p120, p0071 and ARVCF, have also been found in other nonepithelial cells, ${ }^{11,35-37}$ it has been a surprise to find that the adherens junction plaques of all 32 myxomata examined contain an additional major armadillo protein, $\mathrm{Pkp} 2$, which so far has been considered to be a protein exclusive to desmosomes and to the composite junctions of cardiomyocytes. ${ }^{12,17,35,43,44}$ As shown by Goossens et $a l,{ }^{45}$ the cardiomyocyte-specific plaque integration of Pkp2 is based on its binding to myocardial $\alpha$-T-catenin, ${ }^{45}$ a protein, however, that does not seem 
to be present in cardiac myxoma cells. Obviously, the specific molecular binding partners of $\mathrm{Pkp} 2$ and the mechanisms and functions of its acquisition to myxoma adherens junctions will have to be determined in future experiments.

The stable integration of Pkp2 in the adherens junctions of cardiac myxomata is functionally remarkable, as this protein is known as the only member of the plakophilin subfamily that occurs in all proliferatively active epithelial cells and is also an essential architectonic and cytoskeletal filamentanchoring molecule in the desmosomes and composite junctions of myocardial cells. In the latter it is necessary for heart formation and for the onset and coordination of rhythmic heart beat, ${ }^{18,44-48}$ be it directly or indirectly (for further involvements of sodium channels or gap junctions, see also recent knockdown experiments). ${ }^{49-52}$ Most impressive in the discussions about possible functional roles of Pkp2 are certainly the recent reports that cardiac Pkp2 is by far the most sensitive protein, which in mutated forms can contribute to arrhythmogenic ventricular cardiomyopathies (ARVCs). ${ }^{46-53}$ Moreover, in Pkp2 gene knockdown experiments, it has also been shown that its stabilizing effect on cell-cell adhesion in rat cardiomyocyte cultures is so important that a reduction in $\mathrm{Pkp} 2$ can result in a complete separation of the two junctional membranes. ${ }^{49-52}$ Thus, in myxoma tumors growing in a very viscous, mucoid-gelatinous matrix, the acquisition of Pkp2 to the adherens junctions may have an important stabilizing effect and strengthen cell-cell adhesions, in particular those connecting the long and thin cell processes.

Finally, our findings strongly support the hypothesis that cardiac myxoma cells originate from mesenchymal cells of the heart, as their similarity to the cardiac interstitial cells is remarkable. ${ }^{10}$ The molecular marker pattern of cardiac myxomata is indeed very similar to that reported for, for example, valvular interstitial cells in culture, including the extensive and relatively rapid acquisition of Pkp2. Both cardiac interstitial and myxoma cells are also known for a certain spatial or developmental relationship to vascular endothelial cells, and synthesis and secretion of specific endothelial and angiogenic molecules have recently also been ascribed to vascular elements in myxomata. ${ }^{54-56} \mathrm{By}$ contrast, certain neural, neuroendocrine or glandular molecules seen in some elements of these tumors may be differentiation products of some cells 'entrapped' during development (for special discussions see, eg, Johansson, ${ }^{24}$ Kodama et al, ${ }^{34}$ Pucci et $a l,{ }^{40}$ Krikler et $a l,{ }^{57}$ Terracciano et $a l,{ }^{58}$ and Suvarna and Royds ${ }^{59}$ ).

A rather unexpected finding in our study has been the observation of $\mathrm{Pkp} 2$ in all adherens junctions of all 32 cardiac myxomata, whereas we have not detected this junction protein in any of the six noncardiac myxomata, including angiomyxomata of the vagina and the vulva, as well as in skeletal muscle tumors (Supplementary Table 2). Differences of molecular markers and possible cell type-specific histological heterogeneities will be the subject of a future report comparing cardiac with various types of noncardiac myxomata, including cutaneous myxomata and also some of the rare myxoma cases showing malignant behavior, that is, recurrence and metastasis (for general discussions of these problems, see Amano et $a{ }^{20}$ Basso et $a l,{ }^{25}$ Curschellas et $a,^{29}$ Keeling et $a l,{ }^{60}$ Silverman, ${ }^{61}$ Weiss and Goldblum ${ }^{62}$ ).

Although the myxoid nature, with formation of abundant extracellular myxoid matrix, is common to both cardiac and noncardiac myxomata, there seem to be major differences between these tumors, not only with respect to the molecular composition of adherens junctions but also in some general morphological aspects. While cells of cardiac myxomata are often arranged in typical cords, in other myxomatous tumor forms such as intramuscular myxoma and aggressive angiomyxoma, the spindleshaped or stellate tumor cells are loosely distributed and widely separated from each other by myxoid stroma, sometimes seemingly even without any cell-cell contacts (for review see Weiss and Goldblum $^{62}$ ). Therefore, we have decided to start a much broader immunocytochemical comparison between cardiac and noncardiac myxoma tumors, including cases from both sexes and diverse organs.

It has also not escaped our attention that the general occurrence of cadherin-11 and Pkp2 in myxoma adherens junctions may lead to new possible therapeutic concepts of molecular interference with these molecules and thus with cell-cell adhesion and tumor growth. Although surgical excision is-and probably will remain-the standard therapy for the majority of myxoma cases, there are also situations in which the value and availability of pharmacological alternatives should not be underrated (see also Burke et al, ${ }^{41}$ Gaumann et al, ${ }^{56}$ Keeling et al, ${ }^{60}$ Silverman ${ }^{61}$ ). Certainly, recent strategies and preclinical tests with reagents interfering with $\mathrm{N}$-cadherin-mediated cell-cell interactions ${ }^{63}$ and the aforementioned results using the siRNA approach should now also encourage projects interfering with other adherens junction molecules.

\section{Acknowledgements}

We thank Dr Hans Heid (German Cancer Research Center) for his help in the generation of improved polyclonal plakophilin-2 antibodies, as well as Stefanie Winter-Simanowski and Caecilia Kuhn for excellent technical assistance. We also thank Dipl. Biol. Mareike Barth (German Cancer Research Center) for many discussions on cardiac interstitial cells. This work was supported by grants from the Deutsche Krebshilfe (Grants 10-2049-Fr1 and 106976 to WWF). Stefania Rizzo was a visiting fellow at the German Cancer Research Center, 
supported by the Registry of Cardio-Cerebro-Vascular Pathology, Veneto Region, Venice, Italy.

\section{Disclosure/conflict of interest}

The authors declare no conflict of interest.

\section{References}

1 Franke WW, Schmid E, Weber K, et al. HeLa cells contain intermediate-sized filaments of the prekeratin type. Exp Cell Res 1979;118:95-109.

2 Franke WW, Schmid E, Grund C, et al. Antibodies to high molecular weight polypeptides of desmosomes: specific localization of a class of junctional proteins in cells and tissue. Differentiation 1981;20:217-241.

3 Moll R, Franke WW, Schiller DL, et al. The catalog of human cytokeratins: patterns of expression in normal epithelia, tumors and cultured cells. Cell 1982;31: 11-24.

4 Franke WW, Moll R, Mueller H, et al. Immunocytochemical identification of epithelium-derived human tumors with antibodies to desmosomal plaque proteins. Proc Natl Acad Sci USA 1983;80:543-547.

5 Chu PG, Weiss LM. Keratin expression in human tissues and neoplasms. Histopathology 2002;40: 403-439.

6 Miettinen M. Diagnostic Soft Tissue Pathology 1st edn. Churchill Livingstone: New York, Edinburgh, London, Philadelphia, 2003, pp 1-593.

7 Folpe AL, Gown A. Immunohistochemistry for analysis of soft tissue tumors In: Weiss S, Goldblum J (eds). Enzinger and Weiss's Soft Tissue Tumors Vol. 4. St Louis: Mosby, 2001, pp 199-245.

8 Ghadially FN. Diagnostic Electron Microscopy of Tumors. Butterworths: London, Boston, 1980, pp 1-251.

9 Erlandson RA. Diagnostic Transmission Electron Microscopy of Human Tumors. Masson Publishing USA: New York, Paris, Barcelona, 1981, pp 1-193.

10 Barth M, Schumacher H, Kuhn C, et al. Cordial connections: molecular ensembles and structures of adhering junctions connecting interstitial cells of cardiac valves in situ and in cell culture. Cell Tissue Res 2009;337:63-77.

11 Rickelt S, Winter-Simanowski S, Noffz E, et al. Upregulation of plakophilin-2 and its acquisition to adherens junctions identifies a novel molecular ensemble of cell-cell-attachment characteristic for transformed mesenchymal cells. Int J Cancer 2009;125: 2036-2048.

12 Mertens C, Kuhn C, Franke WW. Plakophilins 2a and 2b: constitutive proteins of dual location in the karyoplasm and the desmosomal plaque. J Cell Biol 1996;135:1009-1025.

13 Holmdahl R, Andersson M, Jansson L. A method for the analysis of a large number of specific and multispecific B cell hybridomas derived from primary immunized lymph nodes. Hybridoma 1987;6:197-204.

14 Wuchter P, Boda-Heggemann J, Straub BK, et al. Processus and recessus adhaerentes: giant adherens cell junction systems connect and attract human mesenchymal stem cells. Cell Tissue Res 2007;328:499-514.

15 Neragi-Miandoab S, Kim J, Vlahakes GJ. Malignant tumours of the heart: a review of tumour type, diagnosis and therapy. Clin Oncol (R Coll Radiol) 2007;19:748-756.

16 Pieperhoff S, Franke WW. The area composita of adhering junctions connecting heart muscle cells of vertebrates. VI. Different precursor structures in nonmammalian species. Eur J Cell Biol 2008;87:413-430.

17 Franke WW, Borrmann CM, Grund C, et al. The area composita of adhering junctions connecting heart muscle cells of vertebrates. I. Molecular definition in intercalated disks of cardiomyocytes by immunoelectron microscopy of desmosomal proteins. Eur J Cell Biol 2006;85:69-82.

18 Grossmann KS, Grund C, Huelsken J, et al. Requirement of plakophilin 2 for heart morphogenesis and cardiac junction formation. J Cell Biol 2004;167: 149-160.

19 Stout AP. Myxoma, the tumor of primitive mesenchyme. Ann Surg 1948;127:706-719.

20 Amano J, Kono T, Wada Y, et al. Cardiac myxoma: its origin and tumor characteristics. Ann Thorac Cardiovasc Surg 2003;9:215-221.

21 Jacot-Des-Combes E, Beyeler Y. Cardiac myxoma. Ultrastructural and immunohistochemical study of two cases. Ann Pathol 1982;2:223-228.

22 Takagi M. Ultrastructural and immunohistochemical characteristics of cardiac myxoma. Acta Pathol Jpn 1984;34:1099-1114.

23 Schuger L, Ron N, Rosenmann E. Cardiac myxoma. A retrospective immunohistochemical study. Pathol Res Pract 1987;182:63-66.

24 Johansson L. Histogenesis of cardiac myxomas. An immunohistochemical study of 19 cases, including one with glandular structures, and review of the literature. Arch Pathol Lab Med 1989;113:735-741.

25 Basso C, Valente M, Poletti A, et al. Surgical pathology of primary cardiac and pericardial tumors. Eur J Cardiothorac Surg 1997;12:730-738.

26 Loire R, Tabib A. Histopathologic study of cardiac myxoma. Apropos of 80 surgical cases. Arch Anat Cytol Pathol 1991;39:5-13.

27 Govoni E, Severi B, Cenacchi G, et al. Ultrastructural and immunohistochemical contribution to the histogenesis of human cardiac myxoma. Ultrastruct Pathol 1988;12:221-233.

28 Orlandi A, Ciucci A, Ferlosio A, et al. Cardiac myxoma cells exhibit embryonic endocardial stem cell features. J Pathol 2006;209:231-239.

29 Curschellas E, Toia D, Borner M, et al. Cardiac myxomas: immunohistochemical study of benign and malignant variants. Virchows Arch A Pathol Anat Histopathol 1991;418:485-491.

30 Pucci A, Bartoloni G, Tessitore E, et al. Cytokeratin profile and neuroendocrine cells in the glandular component of cardiac myxoma. Virchows Arch 2003;443:618-624.

31 Ferrans VJ, Roberts WC. Structural features of cardiac myxomas. Histology, histochemistry, and electron microscopy. Hum Pathol 1973;4:111-146.

32 Valente M. Structural profile of cardiac myxoma. Appl Pathol 1983;1:251-263.

33 Stovin PG, Heath D, Khaliq SU. Ultrastructure of the cardiac myxoma and the papillary tumour of heart valves. Thorax 1973;28:273-285.

34 Kodama H, Hirotani T, Suzuki Y, et al. Cardiomyogenic differentiation in cardiac myxoma expressing lineagespecific transcription factors. Am J Pathol 2002;161: 381-389. 
35 Franke WW, Rickelt S, Barth M, et al. The junctions that don't fit the scheme: special symmetrical cell-cell junctions of their own kind. Cell Tissue Res 2009;338:1-17.

36 Franke WW. Discovering the molecular components of intercellular junctions-a historical view In: Nelson J, Fuchs E (eds). Cold Spring Harbor Perspectives in Biology Vol. 1. Cold Spring Harbor Laboratory Press: New York, 2010, pp 1-34.

37 Strumane K, Berx G, Roy FV. Cadherins in cancer In: Behrens J, Nelson WJ (eds). Cell Adhesion Vol. 165. Springer Verlag: Berlin, Heidelberg, New York, 2004, pp 69-103.

38 Butany J, Nair V, Naseemuddin A, et al. Cardiac tumours: diagnosis and management. Lancet Oncol 2005;6:219-228.

39 Reynen K. Cardiac myxomas. N Engl J Med 1995;333:1610-1617.

40 Pucci A, Gagliardotto P, Zanini C, et al. Histopathologic and clinical characterization of cardiac myxoma: review of 53 cases from a single institution. Am Heart J 2000;140:134-138.

41 Burke AP, Heman T, Gomez-Roman JJ, et al. Tumours of the heart. Benign tumors of pluripotent mesenchyme. Cardiac myxoma In: Travis WD, Brambilla E, Müller-Hermelink HK, Harris CC (eds). World Health Organization Classification of Tumours. Pathology and Genetics of Tumours of the Lung, Pleura, Thymus and Heart. IARC Press: Lyon, 2004, pp 260-263.

42 Orlandi A, Ciucci A, Ferlosio A, et al. Increased expression and activity of matrix metalloproteinases characterize embolic cardiac myxomas. Am J Pathol 2005;166:1619-1628.

43 Bass-Zubek AE, Godsel LM, Delmar M, et al. Plakophilins: multifunctional scaffolds for adhesion and signaling. Curr Opin Cell Biol 2009;21:708-716.

44 Borrmann CM, Grund C, Kuhn C, et al. The area composita of adhering junctions connecting heart muscle cells of vertebrates. II. Colocalizations of desmosomal and fascia adhaerens molecules in the intercalated disk. Eur J Cell Biol 2006;85:469-485.

45 Goossens S, Janssens B, Bonne S, et al. A unique and specific interaction between alphaT-catenin and plakophilin-2 in the area composita, the mixed-type junctional structure of cardiac intercalated discs. J Cell Sci 2007;120:2126-2136.

46 Gerull B, Heuser A, Wichter T, et al. Mutations in the desmosomal protein plakophilin-2 are common in arrhythmogenic right ventricular cardiomyopathy. Nat Genet 2004;36:1162-1164.

47 van Tintelen JP, Entius MM, Bhuiyan ZA, et al. Plakophilin-2 mutations are the major determinant of familial arrhythmogenic right ventricular dysplasia/ cardiomyopathy. Circulation 2006;113:1650-1658.

48 Hall C, Li S, Li $\mathrm{H}$, et al. Arrhythmogenic right ventricular cardiomyopathy plakophilin-2 mutations disrupt desmosome assembly and stability. Cell Commun Adhes 2009;16:15-27.

49 Oxford EM, Musa H, Maass $\mathrm{K}$, et al. Connexin43 remodeling caused by inhibition of plakophilin-2 expression in cardiac cells. Circ Res 2007;101: 703-711.

50 Sato PY, Musa H, Coombs W, et al. Loss of plakophilin2 expression leads to decreased sodium current and slower conduction velocity in cultured cardiac myocytes. Circ Res 2009;105:523-526.

51 Joshi-Mukherjee $\mathrm{R}$, Coombs W, Musa $\mathrm{H}$, et al. Characterization of the molecular phenotype of two arrhythmogenic right ventricular cardiomyopathy (ARVC)-related plakophilin-2 (PKP2) mutations. Heart Rhythm 2008;5:1715-1723.

52 Pieperhoff S, Schumacher H, Franke WW. The area composita of adhering junctions connecting heart muscle cells of vertebrates. V. The importance of plakophilin-2 demonstrated by small interference RNA-mediated knockdown in cultured rat cardiomyocytes. Eur J Cell Biol 2008;87:399-411.

53 Marcus FI, Nava A, Thiene G. Arrhytmogenic RV Cardiomyopathy/Dysplasia Recent Advances. Springer Verlag: Milan, 2007, pp 217.

54 Sakamoto H, Sakamaki T, Kanda T, et al. Vascular endothelial growth factor is an autocrine growth factor for cardiac myxoma cells. Circ J 2004a;68:488-493.

55 Sakamoto H, Sakamaki T, Sumino H, et al. Production of endothelin-1 and big endothelin-1 by human cardiac myxoma cells-implications of the origin of myxomas. Circ J 2004b;68:1230-1232.

56 Gaumann A, Strubel G, Bode-Lesniewska B, et al. The role of tumor vascularisation in benign and malignant cardiovascular neoplasms: a comparison of cardiac myxoma and sarcomas of the pulmonary artery. Oncol Rep 2008;20:309-318.

57 Krikler DM, Rode J, Davies MJ, et al. Atrial myxoma: a tumour in search of its origins. Br Heart J 1992;67: 89-91.

58 Terracciano LM, Mhawech P, Suess K, et al. Calretinin as a marker for cardiac myxoma. Diagnostic and histogenetic considerations. Am J Clin Pathol 2000;114: 754-759.

59 Suvarna SK, Royds JA. The nature of the cardiac myxoma. Int J Cardiol 1996;57:211-216.

60 Keeling IM, Oberwalder P, Anelli-Monti M, et al. Cardiac myxomas: 24 years of experience in 49 patients. Eur J Cardiothorac Surg 2002;22:971-977.

61 Silverman NA. Primary cardiac tumors. Ann Surg 1980;191:127-138.

62 Weiss SW, Goldblum JR. Enzinger and Weiss's Soft Tissue Tumors Vol. 4. St Louis: Mosby, 2001, pp 1-1622.

63 Blaschuk OW, Devemy E. Cadherins as novel targets for anti-cancer therapy. Eur J Pharmacol 2009;625: 195-198.

Supplementary Information accompanies the paper on Modern Pathology website (http://www.nature.com/ modpathol) 